\title{
A PROTEÇÃO DO CONSUMIDOR DIANTE DAS PRÁTICAS PUBLICITÁRIAS ABUSIVAS DO COMÉRCIO ELETRÔNICO
}

\author{
THE CONSUMER PROTECTION IN LIGHT OF E-COMMERCE'S ABUSIVE \\ ADVERTISING PRACTICES
}

\author{
Luiz. Carlos Goiabeira Rosa ${ }^{1}$ \\ UFU \\ José Luiz de Moura Faleiros Junior \\ $\mathrm{UFU}$ \\ Rodrigo Luiz da Silva Versiani ${ }^{3}$
}

UFU

\begin{abstract}
Resumo:
A sociedade da informação mudou a forma como se operam as contratações eletrônicas, a ponto de não se questionar mais a imprescindibilidade da Internet e das novas tecnologias para a sequência da evolução das relações sociais. Nesse contexto, normativas de resguardo das contratações assimétricas, como o Código de Defesa do Consumidor, instigam reflexões quanto à necessidade de revisões, notadamente pelo descompasso entre os avanços tecnológicos e o labor legislativo, o que constitui o problema enfrentado nesta pesquisa, cujo presente artigo prestase a analisar a necessidade ou não de se estabelecerem diretrizes mais sólidas que as existentes, para a implementação e consecução das políticas de proteção capazes de prover o equilíbrio entre consumidor e fornecedor. A pesquisa utilizará o método dedutivo, partindo-se de generalidades acerca do comércio eletrônico e se chegando à especificidade da proteção do consumidor diante de tal figura para, ao fim, se demonstrar a complexidade crescente da proteção do consumidor frente às práticas publicitárias abusivas do comércio eletrônico, e a importância da criação de leis específicas para o assunto sem se desconsiderar a suficiência e força do Código Consumerista.
\end{abstract}

Palavras-chave:

Direito do Consumidor. Ciberespaço. Comércio Eletrônico. Práticas abusivas. Publicidade.

\begin{abstract}
:
The information society has changed the way in which electronic contracts operate, to the point of no longer questioning the indispensability of the Internet and new technologies for the evolution of social relations. In this context, rules for safeguarding asymmetric contracts, such as the Consumer Protection Code, instigate reflections on the need for revisions, notably due to the mismatch between technological advances and legislative work, which constitutes the problem faced in this research, whose present article it lends itself to analyzing the need or not to establish more solid guidelines than the existing ones, for the implementation and achievement of protection policies capable of providing the balance between consumer and supplier. The research will use the deductive method, starting from generalities about electronic commerce and reaching the specificity of consumer protection in the face of such figure to, in the end, demonstrate the increasing complexity of consumer protection in the face of abusive advertising practices of commerce electronic, and the importance of creating specific laws for the subject without disregarding the sufficiency and strength of the Consumer Code.
\end{abstract}

\footnotetext{
1 Graduado em Direito pela Universidade Federal de Uberlândia. Pós-graduado lato sensu (Especialização) em Direito Processual Civil pela Universidade Federal de Uberlândia. Mestre em Direito Civil pela Universidade Federal de Minas Gerais. Doutor em Direito Privado pela Pontifícia Universidade Católica de Minas Gerais - PUC Minas. Pós-Doutor em Democracia e Direitos Humanos pela Universidade de Coimbra - Portugal. Professor Associado Nível I da Universidade Federal de Uberlândia, na graduação e na pós-graduação stricto sensu (Mestrado em Direito) da Faculdade de Direito (FADIR/UFU).

2 Mestre em Direito pela Universidade Federal de Uberlândia (UFU). Especialista em Direito Processual Civil, Direito Civil e Empresarial, Direito Digital e Compliance pela Faculdade de Direito Prof. Damásio de Jesus (FDDJ). Participou de curso de extensão em direito digital da University of Chicago. Bacharel em Direito pela Universidade Federal de Uberlândia (UFU). Professor de cursos preparatórios para a prática advocatícia. Pesquisador do Grupo de Estudos em Direito Digital da Universidade Federal de Uberlândia (UFU).

${ }^{3}$ Graduado em Direito pelo Centro Universitário de Patos de Minas - UNIPAM no ano de 2003. Pós-graduado em Direito Civil e Empresarial pela Faculdade de Direito Damásio de Jesus no ano de 2014. Mestrando em Direito pela Universidade Federal de Uberlândia - UFU.
} 
Keywords:

Consumer Law. Cyberspace. E-commerce. Abusive practices. Publicity.

\section{INTRODUÇÃO}

O atual contexto social brasileiro é resultado de um célere estágio de desenvolvimento social, econômico e tecnológico contemporâneo, dando origem à chamada sociedade da informação na qual o comércio eletrônico é propulsionado por elementos capazes de ressignificar o modo de vida comunitário, tornando a realidade hodierna substancialmente diferente daquela de quando foi promulgado o Código de Defesa do Consumidor. Discussões como mapeamentos comportamentais a partir de algoritmos, big data, internet das coisas, proteção de dados pessoais e, destacadamente, os limites da publicidade virtual, são imprescindíveis nesse contexto e desafiam a legislação consumerista, na medida em que a base normativa brasileira, atrelada à tradição romano-germânica, passa a enfrentar dificuldades para se manter em compasso com as transformações sociais proporcionadas pela tecnologia.

Some-se a isso o anseio gerado pelo consumo e a motivação inexorável desdobrada do modelo assimétrico presente nas relações contratuais eletrônicas de consumo, e se estará diante de uma nova maneira de consumir, marcada pelo exacerbado comércio eletrônico afastado da clássica formatação presencial do negócio jurídico, e associada à veiculação de anúncios personalizados aos interesses de cada potencial consumidor a partir de sistemas eletrônicos.

Nesse mister, no curso das últimas décadas dedicou-se grande esforço à formatação de uma fattispecie contratual especialmente destinada às contratações eletrônicas, com grande realce à necessidade de específica proteção jurídica à hipervulnerabilidade do usuário da Internet na formalização de negócios jurídicos. Para além disso, esta preocupação foi acompanhada de novas legislações, interconectadas ao Código de Defesa do Consumidor e voltadas para o delineamento esmiuçado de princípios e diretrizes de utilização da Internet no Brasil, de onde se realça a Lei no 12.965, de 23 de abril de 2014 (o chamado "Marco Civil da Internet") e o Decreto $\mathrm{n}^{\mathrm{o}} 8.771 / 2016$, que a regulamentou, bem como a recente Lei $\mathrm{n}^{\circ} 13.709$, de 14 de agosto de 2018 (a chamada "Lei Geral de Proteção de Dados”), posteriormente alterada pela Medida Provisória $n^{\circ} 869$, de 27 de dezembro de 2018.

Entretanto, a evolução incessante do poder computacional e a presença dos algoritmos despertam olhares para que o chamado direito digital reúna uma série de temas dos mais diversos ramos do direito, sendo desafiado à resolução de inúmeros problemas contemporâneos, sendo a invasão à privacidade e a delimitação de interesses e preferências para fins publicitários o mais preocupante deles. Daí o seguinte questionamento: num contexto consumerista, os 
marcos regulatórios existentes no Brasil são suficientes à pacificação social dos mencionados conflitos?

A esse respeito, o presente artigo presta-se a analisar a necessidade ou não de se estabelecerem diretrizes mais sólidas que as existentes, para a implementação e consecução das políticas de proteção capazes de prover o equilíbrio entre consumidor e fornecedor, notadamente quanto a algumas classes de consumidores tais quais a dos hipervulneáveis, merecendo tratamento diferenciado voltado à prevenção de abusos por parte dos fornecedores de produtos e serviços.

A pesquisa utilizará o método dedutivo, partindo-se de generalidades acerca do comércio eletrônico e se chegando à especificidade da proteção do consumidor diante de tal figura para, ao fim, se demonstrar a complexidade crescente da proteção do consumidor frente às práticas publicitárias abusivas do comércio eletrônico, e a importância da criação de leis específicas para o assunto sem se desconsiderar a suficiência e força do Diploma Consumerista.

\section{NUANCES SOBRE A PROTEÇÃO DO CONSUMIDOR}

As inúmeras contingências e necessidades humanas sempre conduziram o desenvolvimento de novas técnicas e o aprimoramento de institutos, para o fim precípuo de propiciarem a convivência social: "a sociedade evoluiu e daí nasceram incomensuráveis problemas no cotidiano de seus atores em razão da complexidade das relações sociais que acabam por desaguar seus problemas no Direito” (CATALAN, 2012, p. 35). Nesse sentido, Perlingieri (2008, p. 7) aponta que "[a] norma não pode ser compreendida fora da sociedade, historicamente determinada, e a relevância da sociedade civil não pode ser valorada separadamente da norma", em face do que, o sistema normativo sempre deverá acompanhar a evolução da sociedade, buscando adequar-se a esta para que cumpra seu mister de promotor e regulador da ordem e desenvolvimento sociais.

A esse respeito, a partir do momento em que o consumo passou a balizar as relações humanas, começaram a surgir grupos organizados de consumidores - os chamados movimentos sociais - com reivindicações que, no decurso do tempo, moldaram a necessidade de tratamento jurídico específico para tais contingências; de forma semelhante, observou-se tendência à consolidação, por exemplo, de um direito ambiental em torno de demandas protetivas dessas coletividades (RAMSAY, 2001).

Foi nesse contexto que se começou a falar sobre uma sociedade de consumo, para além da mera aquisição de produtos estritamente necessários à sobrevivência. De acordo com 
Bauman (2008, p. 70), a modernidade produziu um modelo estrutural em que a sociedade "[...] 'interpela' seus membros (ou seja, dirige-se a eles, os saúda, apela a eles, questiona-os, mas também os interrompe e 'irrompe sobre’ eles) basicamente na condição de consumidores”, onde estes:

\footnotetext{
Bombardeados de todos os lados com sugestões de que precisam se equipar com um ou outro produto fornecido pelas lojas se quiserem ter a capacidade de alcançar e manter a posição social que desejam, desempenhar suas obrigações sociais e proteger a auto-estima - assim como serem vistos e reconhecidos por fazerem tudo isso -, consumidores de ambos os sexos, todas as idades e posições sociais irão sentir-se inadequados, deficientes e abaixo do padrão a não ser que respondam com prontidão a esses apelos. (BAUMAN, 2008, p. 74).
}

Essa mudança social drástica, ocorrida no âmbito consumerista a partir da transição da modernidade para a pós-modernidade, originou um mercado de consumo revisitado, resultante de inovações técnicas e conceituais que provocaram um repensar dos paradigmas jurídicos privatísticos, desafiando o direito a prover soluções adequadas às novas contingências criadas. Se antes se consumia o necessário para a sobrevivência, passou-se então a se consumir o necessário e o supérfluo, porém este último oferecido sob todo um disfarce de necessidade pelo fornecedor, aí se escondendo de forma astuta a prática comercial abusiva: o consumidor era facilmente seduzido pela propaganda enganosa, sendo por essa induzido a acreditar que o supérfluo era necessário para ser aceito no meio social em que o consumidor vive.

A efetiva proteção ao consumidor tem como um de seus paradigmas a mensagem proferida por John F. Kennedy ao Congresso norte-americano, em 15 de março de 1962, seu marco simbólico de maior proeminência normativa:

Consumidores, por definição, somos todos nós. Eles são o maior grupo econômico, e influenciam e são influenciados por quase toda decisão econômica pública ou privada. Apesar disso, eles são o único grupo importante, cujos pontos de vista, muitas vezes, não são considerados. (MIRAGEM, 2014, p. 38)

Alguns anos depois, em 1973, a Assembleia Consultiva da Comunidade Europeia aprovou a Resolução 543, que deu ensejo à edição da Carta Europeia de Proteção ao Consumidor (STIGLITZ, 1998, p. 54). Por sua vez, a Resolução n 39/248, de 16 de abril de 1985, fruto das discussões do Conselho Social Econômico da Assembleia Geral das Nações Unidas foi o marco fundamental do direito do consumidor, tendo denotado a adesão internacional a uma série de normas dedicadas à proteção ao consumidor (MARTINS; LOTUFO, 2011, p. 167). 
Nesse contexto, a mencionada resolução fomentou a edição de legislações em diversos países, tendo o Brasil seguido referida tendência por ocasião da Assembleia Nacional Constituinte, que cuidou de detalhar o texto final que embasaria a promulgação da Constituição da República Federativa do Brasil de 1988: o constituinte originário consagrou a proteção do consumidor como direito fundamental, elencando-a no artigo $5^{\circ}$, inciso XXXII, e a destacou como princípio geral da atividade econômica, no artigo 170, inciso $\mathrm{V}$ do texto constitucional, bem como traçou a respectiva garantia fundamental no artigo 48 do Ato das Disposições Constitucionais e Transitórias, no qual ficou determinada a criação de um Código de Defesa do Consumidor.

Frise-se que a Constituição Federal trata da proteção ao consumidor também em outros dispositivos, tais quais o artigo 24, inciso VIII, que atribui competência concorrente a União, Estados e Distrito Federal para legislar sobre responsabilidade por dano ao consumidor; o artigo 150, $\int 5^{\circ}$, que determina que a lei estabeleça "medidas para que os consumidores sejam esclarecidos acerca dos impostos que incidam sobre mercadorias e serviços"; o artigo 175, parágrafo único, inciso II, que determina a edição de lei para dispor sobre os direitos dos usuários de serviços públicos; o artigo $220, \$ 4^{\circ}$, que dispõe sobre a propaganda comercial de tabaco, bebidas alcoólicas, agrotóxicos, medicamentos e terapias nos meios de comunicação; o artigo 221, que trata das diretrizes a serem observadas na produção e na difusão de programas de rádio e televisão, além de outros, implícitos, contidos na Carta, tais como o direito à igualdade, o direito de resposta, o direito de acesso à informação, o devido processo legal, a proteção judicial; entre outros.

Fato é que, o Código de Defesa do Consumidor representou um marco importantíssimo para o resguardo dos interesses dos consumidores brasileiros, haja vista que, até então, tudo o que se tinha era um emaranhado de legislações esparsas que não conferiam a proteção necessária. O CDC elevou a defesa do consumidor ao patamar de cláusula pétrea, não podendo, portanto, ser abolida mediante emenda constitucional, o que impede futuras reformas de realizarem alterações em seus princípios fundamentais, máxime porque, o Diploma Consumerista foi editado para tutelar a proteção de um direito fundamental contido em norma constitucional programática.

Conforme Sarlet (2009, p. 262):

Importante ressaltar que, ainda, que, ao utilizarmos a expressão escolhida (normas de cunho programático), o fazemos convictos de que também estas normas são dotadas de eficácia e não podem ser consideradas meras proclamações de cunho ideológico ou político, pois, se assim fosse, efetivamente haveríamos de compartilhar o ponto de vista dos que sustentam 
a inexistência de normas programáticas. Com efeito, já se assinalou alhures que todas as normas constitucionais, mesmo as que fixam programas ou tarefas para o Estado, possuem o caráter de autênticas normas jurídicas, no sentido de que mesmo sem qualquer ato concretizador se encontram aptas a desencadear algum efeito jurídico.

Nesse cenário, a atuação do legislador constituinte, ao inserir a proteção do consumidor no rol de direitos e garantias fundamentais, não somente almejou à criação normativa capaz de atender às necessidades dos consumidores, como também tutelou novas formas de contratação, o que se mostrou crucial devido ao advento da Internet, à democratização do crédito e outras variantes que não foram previamente contempladas por ocasião da criação do Código de Defesa do Consumidor.

\section{CONTRATOS DE CONSUMO NA SOCIEDADE DA INFORMAÇÃO}

$\mathrm{Na}$ Internet, as interações humanas ocorrem de forma completamente peculiar em relação àquelas concernentes ao mundo real. A razão para isto reside no fenômeno descrito por Maslow (1970) em seus estudos sobre as necessidades humanas, perfeitamente enquadráveis no contexto da sociedade da informação, em que é preciso conviver com um novo ambiente chamado de ciberespaço, onde a tecnologia atua como poderoso componente do ambiente de aprimoramento individual.

Na sociologia, Van Dijk (2012 p. 6) Castells (2010, p. 469) foram pioneiros em apontar o papel que a tecnologia desempenharia a partir do recrudescimento de sua presença nas interações pessoais, gerando reflexos no direito. Bem assim, Lessig (2006, p. 214) foi o precursor da proposição de criação de uma Lex Informatica, ao passo que parte da doutrina aventou o surgimento de um fenômeno denominado de "quarta revolução industrial" (SCHWAB, 2016, p. 16), na qual tudo deflagraria a presença de equipamentos eletrônicos, remodelando a vida em sociedade de modo que "em quase todos os lugares onde a vida digital atingiu uma presença real e duradoura, o analógico agora é uma escolha consciente, que requer maior custo, tanto materialmente quanto em termos de nosso tempo e capacidade mental” (SAX, 2017, p. 17).

Conforme se assinalou, há relações jurídicas que são marcadas pela presença de sujeitos passíveis de uma proteção ainda maior. Fala-se em uma hipervulnerabilidade, que caracteriza a relação jurídica de consumo pela presença de indivíduos que, por sua peculiar condição, demandam proteção ainda maior do ordenamento jurídico, como crianças e idosos, não se podendo descartar, ainda, a situação peculiar do usuário da Internet, que, muitas vezes leigo, torna-se suscetível a práticas abusivas. Assim, no despertar da discussão acerca dos limites de 
aplicação das normas jurídicas às relações jurídicas estabelecidas a partir da Internet, perquire-se acerca da efetividade da norma jurídica na regulamentação da propagação de valores, conceitos, bens e serviços que integram a sociedade de consumo na chamada pós-modernidade e que são difundidos ou que passam a existir frente à coletividade de usuários que, direta ou indiretamente, estão em contato com a nova realidade virtual (LORENZETTI, 2004, p. 38).

Com efeito, o ciberespaço pode ser considerado como um ambiente em que se "operam e se autoproduzem regras sociais de comportamento suas e próprias" (ROSSELLO, 2010, p. 618), e, a despeito de nomenclaturas, fato é que grande parte dos usuários da Internet está exposta à publicidade irrefreável, que dá origem à figura do "turboconsumidor" descrito por Lipovetsky e Serroy (2011, p. 57):

\footnotetext{
As classes superiores já não consideram indigno comprar em low cost, e as marcas de luxo são conhecidas e desejadas por todos os grupos, inclusive os mais modestos. As atividades e as paixões transcendem as diferenças sociais, criam "tribos" transversais e diversificadas. As publicações, a publicidade, as ofertas comerciais ecoam isso, visando alvos a uma só vez ampliados a todo o corpo social e segmentados em função de sua inclusão neste ou naquele universo de consumo. O comprador de novo estilo deixou de ser compartimentado e previsível: tornou-se errático, nômade, volátil, imprevisível, fragmentado, desregulado. Porque liberto dos controles coletivos à antiga, o hiperconsumidor é um sujeito zapeador e descoordenado.
}

Denota-se, portanto, que esse cenário também provoca um repensar não só no comportamento do consumidor e do fornecedor, como também quanto à exegese das normas aplicáveis a tanto.

\subsection{As contratações virtuais assimétricas de consumo}

A entabulação de um contrato pressupõe o intercâmbio informacional, para que ocorra o ajuste de interesses que conduz às manifestações bilaterais de vontades e, desta forma, desencadeie-se de forma harmônica a sequência de atos e comportamentos das partes que levem à execução e consecução do objetivo contratual. Nesse mister, tendo-se em vista o avanço da tecnologia e das relações de consumo no plano virtual, o contrato consumerista adquiriu novas feições, sendo mister pontuar que, devido à carência de regulamentação específica, é tido como contrato atípico e de forma livre: embora determinados conteúdos obrigacionais possuam previsão na legislação, como os pactos de compra e venda e de prestação de serviços (LEAL, 2007, p. 82), o contrato eletrônico adquire existência a partir de clicks efetuados pelo mouse do computador, que são registrados e configuram a aceitação (SANTOLIM, 2005, p. 63). 
Denota-se, então, um novo cenário apresentado e configurado pela Internet, em que se constata uma conexão mais abrangente de pessoas, nas mais diversas conjunturas e com os mais variados objetivos, e em circunstâncias que à época da edição do Código de Defesa do Consumidor não existiam, a exemplo das atinentes ao estabelecimento empresarial virtual e da colaboração entre empresas, e ainda, dos contratos conexos. Em essência, se antes o consumidor se relacionava tão somente com o fornecedor imediato, o advento da Internet facultou aos demais participantes da cadeia de fornecimento a respectiva interação direta com o consumidor.

A Internet é, verdadeiramente, um novo ambiente, no qual Lucca (2008, p. 27) afirma habitar "uma nova espécie de consumidor [...] - a do consumidor internauta - e, com ela, a necessidade de proteção normativa, já tão evidente no plano da economia tradicional", ao que Modenesi (2014, p. 315) aponta a figura do "ciberconsumidor", o qual, ainda não familiarizado a um contexto diverso do que se descortina na relação de consumo tradicional, acaba por se superexpor ao consumo virtual, dando margem ao fornecedor proceder com mais intensidade às práticas comerciais abusivas.

Nesse contexto, impõe-se considerar a existência de situações específicas que merecem especial destaque: as relações contratuais assimétricas de consumo, lastreadas na posição de desvantagem ocupada naturalmente pelo consumidor - elo mais fraco da relação de consumo.

\subsection{Práticas publicitárias abusivas e algoritmização}

$\mathrm{Na}$ incansável busca pela viabilização do conhecimento em massa, a informatização possibilita a todas as pessoas o acesso ao conhecimento e, por conseguinte, a sua autorrealização informacional. Nesse mister, sobressai-se o big data, o qual, apesar de não haver um consenso conceitual na literatura específica, tem-se em comum entre os conceitos que se consubstancia num grande e variado volume de dados produzido em grande velocidade e larga escala, condições em que, frequentemente supera a capacidade de absorção e por isso exige constantemente novas formas de processamento para permitir melhores tomadas de decisões, descobertas de conhecimento e otimização de processos (BEYER \& LANEY, 2012, pp. 1-9).

Essa quantidade colossal de dados com que se trabalha, bem como o tratamento dispensado pelas grandes corporações às informações coletadas, tratadas e armazenadas em seus bancos de dados, suscitou em relação ao big data enorme preocupação, traduzida por Pérez Luño (1996, p. 10 e ss.) ao apontar um novo desafio que se colocou diante do ordenamento jurídico: como tutelar os riscos dessa nova realidade? 
Segundo Faria (2001, p. 20), “a revolução das técnicas de comunicação 'diminuiu' o mundo, tornando-o mais independente. Dito de outro modo, tornou-o mais integrado do ponto de vista econômico, porém mais fragmentado do ponto de vista político". Evidentemente, o desconhecimento da população acerca dos procedimentos adotados nas operações de coleta, tratamento e armazenagem desses dados conduz à necessidade de que sejam criados marcos regulatórios como mecanismos necessários para assegurar a plena liberdade do indivíduo na sociedade da informação. A propósito, merecem destaque a iniciativa europeia denominada General Data Protection Regulation (GDPR), editada em 27 de abril de 2016 e que entrou em efeito no dia 25 de maio de 2018, e, no Brasil, a Lei no 13.709, de 14 de agosto de 2018 (Lei Geral de Proteção de Dados - LGPD), alterada pela Medida Provisória no 819, de 27 de dezembro de 2018.

Fato é que, em se tratando de proteção à privacidade, observa-se que, mesmo hoje, com a privacidade consagrada como um direito fundamental, há na Internet uma natural flexibilização de tal direito na medida em que se relativizam os papéis dos contratantes no contrato eletrônico. Bem a propósito é o escólio de Lorenzetti (2004, p. 31):

\begin{abstract}
Este espaço não tem características somente "passivas", mas sim "ativas", no sentido de que exerce influência sobre os demais sistemas. Produz um efeito de “desterritorialização" e "descentralização", porque não há uma relação centroperiferia, não conhece ordens e hierarquias e, sobretudo, não há uma autoridade central. Isso afeta categorias analíticas, como a original-cópia, leitor-autor, fornecedorconsumidor, porque se diz que, ao alterar o espaço, modificam-se os papéis, e o consumidor pode ser um fornecedor.
\end{abstract}

Solove (2008 p. 4) aborda esse tema, reportando-se à expressão "acúmulo de informações" e afirmando que "a profunda proliferação de novas tecnologias de informação durante o século XX [...] fez com que a privacidade surgisse em uma questão de linha de frente em todo o mundo" (tradução nossa). ${ }^{4}$ Ainda segundo o citado autor, inúmeras atividades, sejam elas praticadas por particulares ou pelo Estado, tais como o registro, o uso, a análise, a combinação e, por vezes, a exposição de informações podem ameaçar a privacidade (SOLOVE, 2011, p. 5).

Nesse contexto, Bauman e Lyon (2013, p. 95-96) bem obtemperam ao afirmarem que "os principais meios de obter segurança, ao que parece, são as novas técnicas e tecnologias de vigilância, que supostamente nos protegem, não de perigos distintos, mas de riscos nebulosos e informes". Isto conduz à necessidade de controle e regulação sobre determinadas práticas, embora a carência desses marcos não implique dizer que o ordenamento é lacunoso no que diz respeito à proteção especificamente considerada.

\footnotetext{
${ }^{4}$ No original: "[T] he profound proliferation of new information technologies during the twentieth century [...] made privacy erupt into a frontline issue around the world".
} 
É preciso comentar, ademais, que o domínio da informação em larga escala pertence a um rol seleto de grandes corporações que, realmente, dominam a Internet: são os “impérios da comunicação" descritos por Wu (2010 p. 320-321):

\begin{abstract}
Uma análise minuciosa sugere que a resposta tem menos a ver com alguma atração subliminal obscura por volume e poder do que um impulso muito mais banal; uma preferência incontroversa por conveniência sobre quase qualquer coisa quando se trata de nossas ferramentas de informação. Com cerveja ou carros, sua escolha pode ser uma questão de gosto pessoal; com redes, o único gosto é a conveniência, e isso vem com volume. Ao escolher as opções mais convenientes, coletivamente cedemos o controle a grandes empresas com base em uma série de pequenas escolhas cujas consequências, em resumo, mal consideramos. Hábitos moldam os mercados de forma muito mais poderosa do que as leis. ${ }^{5}$ (tradução nossa)
\end{abstract}

Fala-se até em um fenômeno de dominação pelos hábitos comerciais e pela dependência das pessoas aos serviços fornecidos por essas companhias, como aduz Vaidhyanathan (2011, p. 219) ao analisar o domínio exercido pela Google Inc. sobre os usos da Internet: "nos últimos anos a empresa introduziu grandes mudanças de ênfase em suas prioridades e práticas. Em termos gerais, onde há tempos o Google se especializara em distribuir informações para saciar a curiosidade, agora ele o faz para facilitar o consumo".

Pois, se o Google aparenta onipotência e onipresença - no que outras grandes corporações da Internet seguem o mesmo caminho -, impõe-se ao direito uma troca das lentes pelas quais se observa esse fenômeno, definindo-se marcos regulatórios específicos para que o impacto global dessas corporações não represente riscos à higidez do sistema protetivo conferido pela legislação, principalmente no tocante a direitos fundamentais tais quais a privacidade e a intimidade, por exemplo.

Destarte, num cenário hodierno em que os consumidores estão cada vez mais sofisticados, sensíveis, seletivos e céticos, sendo cada vez mais exigentes e apresentando novos comportamentos que forçam frequentemente a eficácia do marketing praticado na rede, denota-se um desafio às empresas - especialmente quando operam na Internet - a revisitarem suas práticas comerciais e publicitárias, de modo que possam ser verdadeiramente competitivas em face da grande concorrência e, ainda, estejam realmente aptas a assumir e explicitar ao consumidor uma postura confiável, prática e de qualidade de forma a convencer o consumidor a investir no produto oferecido.

\footnotetext{
${ }^{5}$ No original: "Close scrutinity suggests the answer has less to do with some dark subliminal attraction to size and power than an impulse far more banal; an incontrovertible preference for convenience over almost anything when it comes to our information tools. With beer or cars your choice may be a matter of personal taste; with networks, the only taste is convenience, and that comes with size. By choosing the most convenient options we collectively cede control to big firms based on a series of tiny choices whose consequences in sum we scarcely consider. Habits shape markets far more powerfully than laws".
} 
Para cumprir tal meta, as empresas recorrem a recursos tecnológicos que permitem o exercício do chamado marketing segmentado, pelo qual as estratégias empresariais são remodeladas para que se faça determinado anúncio ser apresentado ao consumidor que se saiba ter a necessidade de consumir o produto ou serviço respectivo (LIMEIRA 2003, p. 9) - e isto se faz com mecanismos como machine learning e algoritmos. Nesse sentido, se antes a venda em domicílio era feita de porta em porta, com a entrega de catálogos de produtos pelo próprio vendedor ou por correspondência, hoje tais catálogos adentram a residência do consumidor pela tela do computador.

Outrossim, muito embora a publicidade em si seja uma atividade lícita, é utilizada cada vez mais em detrimento do discernimento do consumidor, recorrendo a práticas que, no extremado propósito de seduzir o comprador a qualquer preço, podem ser consideradas abusivas, tal como se dá por exemplo com a publicidade indutiva, as distorções de informações sobre produtos e serviços, incitação a superstições, violação de valores morais, à segurança, as vendas casadas, dentre outras (LORENZETTI, 2004, p. 390).

É preciso ressaltar que "publicidade" e "propaganda" não se confundem. A primeira visa a um objetivo mercantil ao passo que a segunda vai além, na medida em que possui um viés além do comercial, podendo ser de fundo filosófico religioso, ideológico, social, entre outros. Conforme Ceneviva (1991, p. 20-24), "pretendida que fosse uma distinção terminológica, a propaganda seria espécie do gênero publicidade, consistente em arte ou ciência de indução do consumidor a preferir produto ou serviço cujas qualidades proclama".

Ainda de acordo com o aludido autor, a par desta conceituação torna-se mais claro o escopo da utilização da publicidade na Internet, na medida em que o e-commerce é repensado pela presença de novos instrumentos de marketing, como o uso de áudio e vídeo, a revisão da semiótica aplicada aos anúncios, a utilização de páginas interativas e animadas e até mesmo a contratação de personalidades da Internet, além de outros, como: micro-sites; host sites; jumppages; pop-ups; floaters; banners; adverlogs; rich media; webisodes; marketing viral; e-auctions; gross rating points; bluecasting; e-mail marketing etc. (CENEVIVA, 1991, p. 20-24).

Mas, para além de todas essas ferramentas, a mais importante delas é certamente a utilização de algoritmos para o mapeamento de preferências e comportamentos, conforme indica Wu (2016, p. 267):

O Google e algumas outras empresas da costa oeste demonstraram que a publicidade na web não era apenas exagero: havia dinheiro real a ser feito, revendendo a atenção capturada pela Internet. Mas o Google havia 
efetivamente colocado o AdWords no controle remoto; restava muito mais atenção a ser colhida à moda antiga. ${ }^{6}$

A Internet permite que os anunciantes apresentem aos consumidores em potencial uma grande gama de possibilidades, como o rastreamento das interações, a flexibilidade, que permite ao anunciante lançar, atualizar e até mesmo cancelar uma campanha publicitária imediatamente, e a interatividade que permitem a obtenção de maior engajamento com a marca ou produto pelo uso de plataformas intuitivas destinadas a esse fim (PINHO, 2000, p. 119). Destaca-se, ainda, o alcance internacional da Internet, o que permite a realização de campanhas publicitárias a baixo custo em todos os lugares do planeta, de forma direcionada (PRATES, 2015, p. 52).

Outrossim, as empresas que operam com o comércio eletrônico parecem onipresentes, ofertando mercadorias bem de encontro à vontade e aos interesses do consumidor, tornando inclusive possível adquirirem-se produtos e serviços a qualquer hora do dia ou da noite, a partir de qualquer local, bastando uma conexão à Internet. Isso se dá em grande parte aos sistemas de computador das empresas, os quais são capazes de coletar toda espécie de informação relevante sobre um usuário: de seus dados pessoais, a partir de cadastros realizados em plataformas virtuais, até registros de navegação, gerados em relatórios (logs) que são possíveis pela utilização de cookies.

Conforme Souza (2018, p. 26):

\begin{abstract}
Essencialmente, os cookies são arquivos de texto simples, armazenados pelo navegador frequentado, contendo informações básicas acerca das preferências dos usuários. Num contexto de publicidade comportamental (Online Behavioral Advertising - OBA), tais cookies irão permitir que as empresas publicitárias - e suas parceiras - reconheçam um usuário que retorna posteriormente ao website, o que permitirá, ao longo do tempo, a formação de um perfil consumidor. Levando-se em conta, ainda, as inúmeras possibilidades de processamento dos dados pessoais pelos meios automatizados, tão como a quase ilimitada capacidade de armazenamento, combinação e cruzamento de informações, é possível a formação de quadros de personalidade quase completos, aumentando exponencialmente as hipóteses de consulta e influência nos comportamentos dos indivíduos. Isso expõe ainda mais os usuários na Internet, reforçando a necessidade de estudo e regulamentação legislativa do tema.
\end{abstract}

Com isso, torna-se possível mapear os interesses de determinado usuário para destinar a ele um anúncio moldado especificamente às suas preferências, o que pode levar em conta o período do dia, sua geolocalização, o equipamento que está utilizando - se um computador ou smartphone, por exemplo -, a conexão pela qual está acessando a Internet, dentre outros. E é por isso, em grande parte, que o fornecedor consegue fazer uma publicidade abusiva mas ao mesmo

\footnotetext{
${ }^{6}$ No original: Google and a few other West Coast companies had demonstrated that web advertising wasn't just hype: there was real money to be made reselling attention captured by the Internet. But Google had effectively put AdWords on the remote control; there remained a lot more attention to be harvested the old-fashioned way.
} 
tempo muito sedutora ao consumidor: ao saber das preferências do consumidor, o fornecedor elabora a publicidade com aquilo que o consumidor quer ver e ouvir, ou até mesmo sentir.

\subsection{A proteção consumerista, frente ao comércio digital}

É certo que os consumidores também têm benefícios advindos dessas práticas, sendo o primeiro a disponibilidade de grande acervo de informações da rede, que é apresentado de forma dinâmica e que permite a pesquisa não linear, facilitando o processo de decisão de compra; a facilidade de levantamento, análise e controle de dados sobre os produtos e serviços pesquisados; a redução de preços decorrente da maior competitividade entre fornecedores (PINHO, 2000, p. 120). Entrementes, se por um lado o comércio eletrônico é sem dúvida o meio de fornecimento mais utilizado na atualidade, por outro lado vem ocasionando um vertiginoso aumento da insatisfação do consumidor ante a extrema vulnerabilidade deste último neste tipo de comércio, o que demandaria um reforço protetivo da cadeia de princípios concernentes às práticas publicitárias.

Frente a isso, o Código de Defesa do Consumidor assume posição de proteção, notadamente em virtude da vulnerabilidade do consumidor, elencando diversos princípios relevantes capitaneados pela vulnerabilidade do consumidor no mercado de consumo, a ponto de elencá-la como princípio básico no art. $4^{\circ}$, I. Nesse mister, destaca-se uma das espécies de vulnerabilidade - a informacional, da qual se sobressai o dever do fornecedor em informar adequadamente o consumidor, conforme preceitua ao art. $6^{\circ}$, III, na medida em que preconiza ser direito do consumidor "[...] a informação adequada e clara sobre os diferentes produtos e serviços, com especificação correta de quantidade, características, composição, qualidade, tributos incidentes e preço, bem como sobre os riscos que apresentem" (BRASIL, 1990).

De tal relevância é o dever de informação na relação de consumo, que tal mister resta previsto em várias ocasiões no decorrer do CDC, a exemplo dos arts. $6^{\circ}$, III; 31; 46; 54; entre outros. E nessa qualidade, o dever de informar é imposto ao fornecedor não só na fase contratual, mas também e principalmente na fase pré-contratual, onde o consumidor ainda está a confirmar a sua vontade pela aquisição do produto ou do serviço. Não é demais lembrar que a relação de consumo não se restringe ao contrato de consumo, pois, conforme Nery Júnior (2011, p. 512), o CDC não fala de "contrato de consumo", "ato de consumo", "negócio jurídico de consumo", mas de relação de consumo, termo que tem sentido mais amplo do que aquelas expressões. 
Assim, tratando-se de relação de consumo, o fornecedor possui deveres correlatos aos direitos básicos do consumidor desde a oferta do produto ou serviço, isto é, desde a fase précontratual. Nesse mister, dentre tais obrigações está o dever de informar o consumidor acerca dos encargos do contrato conforme o art. $6^{\circ}$ do CDC (BRASIL, 1990), ao estabelecer no inciso III ser direito básico do consumidor a "informação adequada e clara sobre os diferentes produtos e serviços, com especificação correta de quantidade, características, composição, qualidade, tributos incidentes e preço, bem como sobre os riscos que apresentem".

Destarte, na fase pré-contratual tem o fornecedor o dever precípuo de informar ao consumidor sobre circunstâncias e fatores que onerem o fornecimento do produto ou serviço além do normalmente esperado pelo consumidor mediano, para que este manifeste sua vontade sem vícios de consentimento. Posto de outra forma, Filomeno (2011, p. 154) bem obtempera que o fornecedor tem o dever de informar previamente o consumidor:

[...] sobre especificações corretas de quantidade, características, composição, qualidade e preç,o, bem como sobre os riscos que apresentem, obrigação específica dos fornecedores de produtos e serviços. Trata-se, repita-se, do dever de informar bem o público consumidor sobre todas as características importantes de produtos e serviços, para que aquele possa adquirir produtos, ou contratar servic,os, sabendo exatamente o que poderá esperar deles.

E tal obrigação resta patente na fase pré-contratual, pois é nesse momento em que o fornecedor tem a oportunidade de prestar adequadamente as informações sobre o produto ou serviço oferecido ao consumidor, o qual, ao manifestar sua vontade em celebrar o contrato, somente o fará validamente se antes tiver sido suficientemente informado sobre todas as vantagens e encargos do produto ou serviço.

É essa a diretriz do art. 31 do CDC (BRASIL, 1990):

Art. 31. A oferta e apresentação de produtos ou serviços devem assegurar informações corretas, claras, precisas, ostensivas e em língua portuguesa sobre suas características, qualidades, quantidade, composição, preço, garantia, prazos de validade e origem, entre outros dados, bem como sobre os riscos que apresentam à saúde e segurança dos consumidores.

Infira-se que, em complemento aos arts. $4^{\circ}$, I e $6^{\circ}$, III, o art. 31 é incisivo em impor ao fornecedor o dever de prestar informações exatas sobre o produto ou serviço, sob pena de não restar configurada a livre vontade do consumidor na celebração do contrato. Conforme bem explica Benjamin (2011, p. 289), ao comentar sobre o aludido artigo:

Para a proteção efetiva do consumidor não é suficiente o mero controle da enganosidade e abusividade da informação. Faz-se necessário que o fornecedor cumpra 
seu dever de informação positiva. Toda a reforma do sistema jurídico nessa matéria, em especial no que se refere à publicidade, relaciona-se com o reconhecimento de que o consumidor tem direito a uma informação completa e exata sobre os produtos e serviços que deseja adquirir. $O$ dispositivo tem, na sua origem, o princípio da transparéncia, previsto expressamente pelo CDC (art. $4^{\circ}$, caput). Por outro lado, é decorrência também do princípio da boa-fé objetiva, que perece em ambiente onde falte a informação plena do consumidor. Com efeito, "na sociedade de consumo o consumidor é geralmente mal informado. Ele não está habilitado a conhecer a qualidade do bem ofertado no mercado, nem a obter, por seus próprios meios, as informações exatas e essenciais. Sem uma informação útil e completa, o consumidor não pode fazer uma escolha livre. A obrigação que o Direito Civil impõe ao comprador de informar-se antes de contratar é, na sociedade de consumo, irreal”.

Em complemento, Menezes Cordeiro (2005, p. 549) bem observa que:

\begin{abstract}
A conclusão de um contrato na base de falsas indicações, de informação deficiente ou, até, de ameaças ilícitas, independentemente da aplicabilidade do regime próprio dos vícios na formação da vontade, implica o dever de indemnizar, por culpa na formação dos contratos. Este dever de esclarecimento tem intensidade particular quando um contratante surja, perante outro, como carecido de protecção especial.
\end{abstract}

Ou seja: conforme o citado doutrinador, se o contrato é precedido de informação deficiente, é defeituoso em sua formação e não pode ser convalidado, máxime se uma das partes for vulnerável - no caso, o consumidor.

Assim, o fornecedor falta com o dever de informação e por isso vicia a vontade do consumidor se, no fornecimento do produto ou serviço, adota expediente que onera o preço final de modo diverso do normalmente esperado pelo consumidor mediano e a este não informa ou informa deficientemente previamente e de forma clara, exata e precisa tal oneração, dado que a transparência é um dos pressupostos de validação do contrato e o dever de informação é uma decorrência lógica, e sendo o consumidor mediano tal qual o Autor o é, desprovido de conhecimento técnico e específico acerca de especificidades contratuais, é vulnerável conforme a dicção do art. $4^{\circ}$, inciso I, do CDC e não pode ter considerada válida sua vontade em celebrar o contrato se não fora informado adequadamente sobre o contrato.

Ato contínuo, somente após a devida, exata e completa informação é que se poderá afirmar que o consumidor manifestou validamente sua vontade pela celebração do contrato, pois então não terá dúvidas e nem ideias equivocadas acerca do produto ou serviço ofertado, e nem quanto à forma de obtê-lo, no que doutrina e jurisprudência convencionaram denominar consentimento informado ou vontade qualificada.

Essa proteção se espraia ao longo do CDC, por meio de outros expedientes dentre os quais a identificação da publicidade (artigo 36); vinculação contratual da publicidade (artigos 30 e 35); veracidade (artigo 37, $\$ 1^{\circ}$ ); não abusividade da publicidade (artigo 37, $\$ 2^{\circ}$ ); inversão do ônus da prova (artigo 38); transparência da fundamentação publicitária (artigo 36, parágrafo único); 
correção do desvio publicitário (artigo 56, XII); entre outros. Ainda, e conforme se salientou anteriormente, com relação ao direito de arrependimento, o artigo 49 do CDC já contém norma impositiva específica; e outras práticas, como cobranças, segurança nos dados e no pagamento, também estão contempladas pela previsão dos artigos 42, 43 e 52 do CDC. Entretanto, existe o desafio de trazer tal proteção para o e-commerce, conforme aduz Marques (2012, p. 340) ao afirmar ser:

[...] imprescindível a introdução de uma seção específica sobre a proteção dos consumidores no âmbito do comércio eletrônico, em razão de sua expressiva utilização. Se, à época da promulgação do Código de Defesa do Consumidor, o comércio eletrônico nem sequer existia, atualmente é o meio de fornecimento a distância mais utilizado, alcançando sucessivos recordes de faturamento. Porém, ao mesmo tempo ocorre o aumento exponencial do número de demandas dos consumidores. As normas projetadas atualizam a lei de proteção do consumidor a essa nova realidade, reforçando, a exemplo do que já foi feito na Europa e nos Estados Unidos, os direitos de informação, transparência, lealdade, autodeterminação, cooperação e segurança nas relações de consumo estabelecidas através do comércio eletrônico. Busca-se ainda a proteção do consumidor em relação às mensagens eletrônicas não solicitadas (spams), além de exercitar o exercício de direito de arrependimento.

É preciso destacar que há, no Brasil, uma regulamentação especificamente voltada para o comércio eletrônico: o Decreto n ${ }^{\circ}$ 7.962, de 15 de março de 2013, regulamentando o CDC no que tange à contratação no âmbito do comércio eletrônico. Contudo, conforme Teixeira (2015, p. 83):

[...] referido decreto não cuida com precisão da extensão da responsabilidade civil nas compras pela internet, cujo tema está pautado fundamentalmente pelo Código Civil, arts. 927 e 931, e pelo Código de Defesa do Consumidor (CDC, especialmente os arts. 12 e 13). De qualquer forma, a doutrina é uniforme quanto à admissibilidade da aplicação do ordenamento jurídico brasileiro às relações estabelecidas no comércio eletrônico.

Nesse mister, visando à tutela de novas situações jurídicas tais como a ora apresentada e atento à necessidade de aperfeiçoar o Código no que tange a situações da atualidade, o Senado Federal instituiu uma Comissão de Juristas para atualizar o CDC, onde, dentre os vários temas abarcados, abrangeu o comércio eletrônico (PLS nº 281/2012).

Para Lorenzetti (2004, p. 75):

O modelo do paraíso democrático baseado no livre acesso e intercâmbio de opiniões pode ser uma situação meramente transitória e fugaz. Rapidamente surgem portais e sítios que canalizam a maioria das mensagens num crescente processo de concentração, viabilizado pela concessão de direitos de propriedade intelectual sobre inúmeros bens imateriais. O funcionamento da Internet não é uma questão meramente privada; é uma forma externa da globalização, com efeitos políticos e sociais que envolvem a ordem pública e a necessidade de regulação. Não se trata de 
patrocinar intervenções distorcidas, mas sim intervenções institucionais, com o escopo de resguardar a privacidade, o consumo, a moral, o tratamento igualitário e não discriminatório.

Nesse contexto, proteger e melhorar a posição jurídica contratual do negociador mais fraco e leigo no comércio eletrônico, que é o consumidor pessoa física residente no Brasil, parece ser a finalidade maior da doutrina brasileira e dos projetos de lei existentes sobre o assunto. Marques (2011, p. 126-127) bem alude a respeito:

\footnotetext{
Sejam consideradas ofertas de consumo ou não, há que se considerar que estas práticas comerciais dos fornecedores fazem nascer deveres de boa-fé geral, como o de informação, identificação de oferta comercial, cuidado com os dados do consumidor (dever de privacidade do consumidor, de proteção contra invasões no site ou na rede) e deveres de boa-fé específicos do meio virtual, com o de confirmação individual, de perenização da oferta e do contrato, e deveres de cooperação na comunicação (o silêncio do fornecedor pode ser usual no comércio, mas é fonte de insegurança e quebra da confiança perante o consumidor), na execução a distância (geralmente por correio e outros meios de execução da prestação característica, que é a do fornecedor) e no pagamento a distância (cuidados ao retirar a quantia do cartão de crédito, com número do cartão de crédito etc.).
}

Até o término da elaboração deste estudo, tem-se conhecimento de que, sobre a tramitação dos aludidos projetos de lei, no dia 30 de setembro de 2015, o Senado Federal aprovou os projetos que dizem respeito a comércio eletrônico (PLS n. 281/2012), crédito e superendividamento (PLS n. 283/2012), tendo os textos sido aprovados na forma de substitutivo, e estes foram encaminhados à Câmara dos Deputados para revisão, nos termos do artigo 65 da Constituição da República, recebendo os projetos de leis naquela casa legislativa os respectivos números: PL n. 3.514/2015 (comércio eletrônico) e PL n. 3.515/2015 (crédito e superendividamento).

\section{CONCLUSÃO}

No curso dessa pesquisa, apontou-se, em brevíssimas linhas, como a atualidade conjuntural da sociedade brasileira já se encontra permeada pela tecnologia e pela Internet, que modificaram sensivelmente a forma como certas práticas comerciais são realizadas, com destaque para o comércio eletrônico, incessantemente propulsionado por elementos capazes de alavancar a publicidade realizada na rede a partir de práticas que, embora lícitas em primeira análise, podem se revelar abusivas a depender da forma como são realizadas.

Para além de várias ferramentas de marketing utilizadas hodiernamente, pontuou-se como os mapeamentos comportamentais a partir de algoritmos fomentados pelo já mencionado big data, e pela presença da internet das coisas, propiciam esse direcionamento de anúncios 
personalizados, que lança ao direito a preocupação com a violação do direito fundamental à privacidade.

Com isso, os limites da publicidade virtual foram revisitados para que se pudesse indagar de sua imprescindibilidade na hodierna sociedade da informação, desafiando a legislação consumerista, na medida em que a base normativa brasileira, atrelada à tradição romanogermânica, passa a enfrentar dificuldades para se manter em compasso com as transformações sociais proporcionadas pela tecnologia, o que tem instigado o legislador a editar marcos regulatórios específicos, como o Marco Civil da Internet e a Lei Geral de Proteção de Dados.

A isso se soma a dificuldade de tutela específica de novas práticas que surgem a todo momento, haja vista a celeridade com que a tecnologia se modifica e a flexibilidade dos influxos publicitários na Internet. Outrossim, questionou-se quanto aos limites da atuação das grandes corporações em torno de práticas publicitárias que podem se convolar em abusividades.

O novo direito digital é cada vez mais marcado pelo anseio por tais marcos regulatórios, e já se questiona acerca da suficiência do Código de Defesa do Consumidor para a tutela de certas relações jurídicas. Nesse campo, a reforma do CDC que tramita perante o Congresso Nacional foi apresentada, em linhas gerais, com ênfase ao novo trato que se busca conferir às práticas do comércio eletrônico. Mas, fato é que as normativas existentes, especialmente o Código de Defesa do Consumidor, já formam um microssistema aglutinador de preceitos desdobrados do forte acervo de princípios protetivos, inclusive em nível constitucional, que parece apto a conferir proteção em hipóteses específicas.

É natural que sejam criadas leis especialmente voltadas a contingências como a guarda de registros de navegação e utilização, os vazamentos de dados, a necessidade de anonimização e outros, mas todos esses temas já poderiam ser enfrentados pela legislação consumerista mesmo antes do advento do Marco Civil ou da LGPD. E tal hipótese investigada se revelou parcialmente verdadeira, na medida em que o esforço legislativo em torno da criação dessas normativas específicas jamais conseguirá se manter pari passu à evolução tecnológica. Então, melhor do que regular situações jurídicas cada vez mais específicas, melhor seria recorrer à execução e à fiscalização do cumprimento das normas já existentes.

Aduza-se que, para a proteção efetiva do consumidor, não basta o tratamento jurídico conferido pela norma vigente à enganosidade e à abusividade da informação, fazendo-se necessário que o fornecedor cumpra seu dever de informação em caráter positivo, de modo que toda a reforma do sistema jurídico nessa matéria, especialmente no que se refere à publicidade, está relacionada ao reconhecimento do fato de o consumidor ter direito de receber informações completas e exatas sobre os produtos e serviços que deseja adquirir, pois somente assim se terá 
o fácil entendimento, a simplificação informativa (em detrimento da prolixidade) e o caráter ostensivo almejado pela norma, sujeitando-se o infrator às reprimendas (inclusive nas searas administrativa e penal) para o caso de descumprimento.

\section{REFERÊNCIAS}

BAUMAN, Zygmunt; LYON, David. Vigilância líquida. Trad. Carlos Alberto Medeiros. Rio de Janeiro: Zahar, 2013.

BAUMAN, Zygmunt.. Vida para consumo: a transformação das pessoas em mercadoria. Trad. Carlos Alberto Medeiros. Rio de Janeiro: Zahar, 2008.

BENJAMIN, Antônio Herman de Vasconcellos e. Das práticas comerciais. In GRINOVER, Ada Pellegrini et al.. Código Brasileiro de Defesa do Consumidor - comentado pelos Autores do Anteprojeto. 10. ed.. Rio de Janeiro: Forense, 2011, v. 1.

BEYER, Mark; LANEY, Douglas. The importance of "Big Data": a definition. Stamford: Gartner Publications, 2012.

CASTELLS, Manuel. The rise of the network society: information age. 2. ed. Oxford: Blackwell, 2010, v. 1.

CATALAN, Marcos Jorge. Descumprimento contratual: modalidades, consequências e hipóteses de exclusão do dever de indenizar. Curitiba: Juruá, 2012.

CENEVIVA, Walter. Publicidade e direito do consumidor. São Paulo: Revista dos Tribunais, 1991.

FARIA, José Eduardo. Informação e democracia na economia globalizada. In: SILVA JUNIOR, Ronaldo Lemos; WAISBERG, Ivo (Org.). Comércio eletrônico. São Paulo: Revista dos Tribunais, 2001.

FILOMENO, José Geraldo. Dos direitos básicos do consumidor. In GRINOVER, Ada Pellegrini et al.. Código Brasileiro de Defesa do Consumidor - comentado pelos Autores do Anteprojeto. 10. ed.. Rio de Janeiro: Forense, 2011, v. 1.

LEAL, Sheila do Rocio Cercal Santos. Contratos eletrônicos: validade jurídica dos contratos via Internet. São Paulo: Atlas, 2007.

LESSIG, Lawrence. Code 2.0. 2. ed. Nova Iorque: Basic Books, 2006.

LIMEIRA, Tânia M. Vidigal. E-marketing na Internet com casos brasileiros. São Paulo: Saraiva, 2003.

LIPOVETSKY, Gilles; SERROY, Jean. A cultura-mundo: resposta a uma sociedade desorientada. Trad. Maria Lúcia Machado. São Paulo: Cia. das Letras, 2011. 
LORENZETTI, Ricardo Luis. Comércio eletrônico. Trad. Fabiano Menke. São Paulo: Revista dos Tribunais, 2004.

MARQUES, Cláudia Lima. Contratos no Código de Defesa do Consumidor: o novo regime das relações contratuais. 6. ed. São Paulo: Revista dos Tribunais, 2011.

MARQUES, Cláudia Lima; MIRAGEM, Bruno. Anteprojetos de lei de atualização do Código de Defesa do Consumidor. Revista de Direito do Consumidor, São Paulo: Revista dos Tribunais, v. 21, n. 82, p. 331-358, abr./jun. 2012.

MENEZES CORDEIRO, Antônio. Tratado de Direito Civil Português. Parte Geral. Coimbra: Almedina, 2005, t. 1.

MARTINS, Fernando Rodrigues. Constituição, direitos fundamentais e direitos básicos do consumidor. In: MARTINS, Fernando Rodrigues; LOTUFO, Renan (Orgs.) 20 anos do Código de Defesa do Consumidor. São Paulo: Saraiva, 2011.

MASLOW, Abraham Harold. Motivation and personality. 2. ed. Nova Iorque: Harper \& Row, 1970.

MIRAGEM, Bruno. Curso de direito do consumidor. 5. ed. São Paulo: Revista dos Tribunais, 2014.

MODENESI, Pedro. Contratos eletrônicos de consumo: aspectos doutrinário, legislativo e jurisprudencial. In: MARTINS, Guilherme Magalhães; LONGHI, João Victor Rozatti (Coords.). Direito digital: direito privado e Internet. 2. ed. Indaiatuba: Foco, 2019.

NERY JÚNIOR, Nelson. Da proteção contratual. In GRINOVER, Ada Pellegrini et al.. Código Brasileiro de Defesa do Consumidor - comentado pelos Autores do Anteprojeto. 10. ed.. Rio de Janeiro: Forense, 2011, v. 1.

PÉREZ LUÑO, Antonio-Enrique. Manual de informática e derecho. Barcelona: Ariel, 1996.

PERLINGIERI, Pietro. O direito civil na legalidade constitucional. Trad. Maria Cristina de Cicco. Rio de Janeiro: Renovar, 2008.

PINHO, José Benedito. Publicidade e vendas na Internet: técnicas e estratégias. São Paulo: Summus, 2000.

PRATES, Cristina Cantú. Publicidade na Internet: consequências jurídicas. Curitiba: Juruá, 2015.

RAMSAY, Iain. Consumer protection in the era of informational capitalism. In: WILHELMSSON, Thomas; TUOMINEM, Salla; TUOMOLA, Heli (Ed.). Consumer law in the information Society. Haia: Kluwer Law International, 2001, p. 45-65.

ROSSELLO, Carlo. Riflessioni. De jure condendo in materia di responsabilità del provider. I1 Diritto dell'Informazione e Dell'Informatica, Roma, v. 26, n. 6, p. 617-629, nov./dez. 2010. 
SANTOLIM, Cesar Viterbo Matos. Os princípios de proteção do consumidor e o comércio eletrônico no direito brasileiro. Revista de Direito do Consumidor, São Paulo: Revista dos Tribunais, v. 14, n. 55, p. 53-84, jul./set. 2005.

SARLET, Ingo Wolfgang. A eficácia dos direitos fundamentais. 10. ed. Porto Alegre: Livraria do Advogado, 2009.

SAX, David. A vingança dos analógicos: por que os objetos de verdade ainda são importantes. Trad. Alexandre Matias. Rio de Janeiro: Anfiteatro, 2017.

SCHWAB, Klaus. The fourth industrial revolution. Genebra: World Economic Forum, 2016.

SOLOVE, Daniel J.. Nothing to hide: the false tradeoff between privacy and security. New Haven: Yale University Press, 2011.

SOLOVE, Daniel J.. Understanding privacy. Cambridge: Harvard University Press, 2008.

STIGLITZ, Gabriel. Protección jurídica del consumidor. 2. ed. Buenos Aires: De Palma, 1988.

SOUZA, Thiago Pinheiro Vieira de. A proteção de dados como direito fundamental e a incivilidade do uso de cookies. 2018. 65f. Trabalho de Conclusão de Curso (Graduação em Direito) - Universidade Federal de Uberlândia, Uberlândia, 2018.

TEIXEIRA, Tarcísio. Comércio eletrônico: conforme o Marco Civil da Internet e a regulamentação do e-commerce no Brasil. São Paulo: Saraiva, 2015.

VAIDHYANATHAN, Siva. A Googlelização de tudo (e por que devemos nos preocupar): a ameaça do controle total da informação por meio da maior e mais bem-sucedida empresa do mundo virtual. Trad. Jefferson Luiz Camargo. São Paulo: Cultrix, 2011.

VAN DIJK, Jan. The network society. 3. ed. Londres: Sage Publications, 2012.

WU, Tim. The attention merchants: the epic scramble to get inside our heads. Nova Iorque: Vintage, 2016.

WU, Tim. The master switch: the rise and fall of information empires. Nova Iorque: Vintage, 2010. 